\title{
Staff Rationalisation in Public Sector: A Case Study of Nigerian Postal Service Nipost Sokoto Territory
}

\author{
Anwar Ali Shah G. Syed ${ }^{1}$, Noman Abid Lakhani ${ }^{2}$, Lawal Muhammad Anka ${ }^{3} \&$ F. M. Shaikh ${ }^{4}$ \\ ${ }^{1}$ Daddu-Campus, University of Sindh, Jamshoro, Pakistan \\ ${ }^{2}$ Institute of Business \& Technology, Karachi, Pakistan \\ ${ }^{3}$ Zamfara Agricultural and Rural Development Authority, Samaru Gusau, Zamfara State, Nigeria \\ ${ }^{4} \mathrm{Z}$ A Bhutto Agricultural College, Dokri, Sindh, Pakistan \\ Correspondence: F. M. Shaikh, Z A Bhutto Agricultural College, Dokri, Sindh, Pakistan. E-mail: \\ faizanmy2000@hotmail.com
}

\author{
Received: March 14, 2012 Accepted: May 27, 2012 Online Published: October 18, 2012 \\ doi:10.5539/ass.v8n13p99 URL: http://dx.doi.org/10.5539/ass.v8n13p99
}

\begin{abstract}
The study examined the view of junior and senior staff of NIPOST regarding staff rationalisation in public service with special reference to Sokoto territory. To achieve this, the study examined the criteria and reason for staff rationalisation, identifies the category of people involved in the exercise, investigates whether staff rationalisation has instilled discipline and brought about efficiency and effectiveness in the organisation. This research is based on information obtained from available records, personal observation and interview conducted. The major conclusion drawn from this paper was the main reason for staff rationalisation is to cut down expenses and reduce redundancy of staff to source for money and to prepare the organisation towards commercialisation. Survey results revealed that $70 \%$ of the respondents are of the view that there is improvement in the postal services in areas of delivery of mails by postmen. While $30 \%$ agreed that there was no improvement. Available records have shown that 65 junior staff from Sokoto Territory lost their jobs either through retrenchment or dismissal, about 10 senior staff lost their jobs in the same form of termination. Senior Officers in managerial cadre are not affected in the exercise. Most of the respondents believe that there was politics in the whole exercise. Finally, efficiency and effectiveness have not been achieved in NIPOST Sokoto Territory because rationalisation was not properly carried out. Null hypothesis $\mathrm{H}_{0}$ it is accepted and alternate hypothesis $\mathrm{H}_{\mathrm{A}}$ is rejected.
\end{abstract}

Keywords: staff, rationalisation, post services

\section{Introduction}

There has been the need for improvement in the Nigerian Public Service in the 1970 and 1990s. The Udoji Commission though the public service was deficient in at least three major areas. Firstly, there was the need to recruit and retrain specialists; secondly, there was the need for conception of new management of the public service and thirdly the new public service was to motivate them to achieve defined goals more effectively. These must make public service a better place to work so that employees will be inspired to give their best as members of team engaged in common enterprises for the public good (Anka, 1992).

Scholars in public administration believe there are several factors responsible for failure of the Nigerian civil service; they are faulty recruitment of employees, faulty posting and frequent postings, inadequate training, deterioration in health incompetent superior, lack of helpful political direction, massive purge of civil service and false reporting (Anka, 2006).

The admission by government that cooperation has been incompetently managed has led to a demand from the private sector for their privatisation. If the corporation can not survive without regular government subventions and capital investments and these can no longer be guaranteed, surely rationalisation and privatisation become a viable option (Nadia and Appelbaum, 2006).

The most prominent step towards rationalisation started in 1975. The purpose was based on ill-health, old age, indiscipline, divided loyalty, corruption, declining productivity and redundancy (Anka, 1988). 
In $1984-85$, the Nigerian public services witness another purge. This reform was repeated by massive retrenchment of public servants which was aimed at clearing the public service of dead woods, corrupt elements and rejuvenating the service for the challenges ahead. Nigerian Postal Service (NIPOST) since 2000 has always experienced a lot of problem in the area of payment of salaries and maintenance of vehicles. With the emergence of private carrier companies leaving NIPOST with low revenue base (NIPOST Annual Report, 2005).

NIPOST today does not receive subventions from Federal Government but is left to generate revenue for maintenance of the organisation, because NIPOST was created to render more of social services than financial profits. Now that the organisation has to generate enough revenue to [pay staff salaries and other maintenance costs, it has to commercialise its services including sales of postage stamps. A major approach to commercialisation NIPOST embarked upon is staff rationalisation (NIPOST Annual Report, 2010).

NIPOST Sokoto Territory like other territories in the Federation was given a responsibility to compile a list of those to be affected by the rationalisation process but this might have final decision. For this reason, staff rationalisation process was carried in Sokoto Territory.

\subsection{Problem Statement}

The Nigerian Postal Service was established to render postal service to the Nigerian public that is efficient, effective, reliable and affordable. Since its inception, NIPOST has not been able to reach the said target; this could be due to inefficiency on part of the organisation and lack of proper funding by the government. NIPOST with the aim of rendering social services nearer to the people, such offices do not appear to generate salaries and maintain vehicles.

With the establishment of Decree No. 25 of $6^{\text {th }}$ July 1988 which establish and empowered Technical Committee on Privatisation and Commercialisation (TCPC) to implement and monitor the programme of commercialisation and privatisation of public enterprises, NIPOST started to retrench some staff based on the criteria mentioned above. The reform programme is implemented with a view to help in improving efficiency and effectiveness towards commercialisation in NIPOST Sokoto Territory.

\subsection{Objective of the Study}

The objectives of the study were to:

- Examine the main reason for commercialisation of NIPOST.

- Assess the criteria used for retrenchment of NIPOST.

- Identify the category of people retrench in NIPOST Sokoto Territory

- Investigate whether staff rationalisation has instilled discipline and brought out efficiency and effectiveness in NIPOST Territory.

\subsection{Hypothesis}

$\mathrm{H}_{\mathrm{o}} \quad$ If efficiency and ineffectiveness are on increase in NIPOST Sokoto Territory, then staff rationalisation was not carried out.

$\mathrm{H}_{\mathrm{A}}$ If efficiency and ineffectiveness are achieved in NIPOST Sokoto Territory, then staff rationalisation was properly carried out

\subsection{Scope and Limitation of the Study}

To fully examine rationalisation exercise in NIPOST Sokoto Territory was used as a unit of analysis. One of the limitations of this study was that very little if any has been done on staff rationalisation in public service in Nigeria and NIPOST in particular. Other works generally centres on efficiency of services NIPOST provide to the Nigerian public. There was also the problem of cooperation on part of staff to give detail opinion about staff rationalisation.

\section{Review of Literature}

Mc Graw Hill (1965) defined rationalisation as the use of scientific management and industrial organisations in production. Rationalisation to him was based on the theory that a large, well-organised firm would advice certain economics of scale and that the competition of small industrial units was wasteful. According to MC Graw Hill the use of advance technological methods of production was the most common form of rationalisation.

Rationalisation therefore is a process of organising an industry to achieve greater efficiency and economy; organisations are re-organised based on some reasons which may be to cut down expenses and achieve efficiency and effectiveness. 


\subsection{Corporate Restructuring}

Naschold (1996) believes that there is room for substantial improvement in public sector productivity. However, he is sceptical about the effectiveness of specific reform initiates in unlocking that potential. Naschold further observed that potential dangers may arise when private sector models are applied to public sector organisations. Although put emphasises on potential weakness of privatisation, he believes that public agencies must put more emphasis on efficiency and effectiveness. To achieve greater efficiency, organisations ought to adopt reforms that are central to this new paradigm such as segmentation of policy and operational functions and more expensive use of contracting out.

Dia (1970) recommended performing client consultations to assess public views on public agency reform and to determine the feasibility and relevance of public programmes. According to him enterprises can improve performance through managerial statutory worker guideline which help neutralise the myth of all powerful managers and this enhances transparency in company activities.

\subsection{Reasons for Resistance to Change in Organisations}

Change is necessary inn organisations because the intentions of planned change will be heavily dependent upon the previous experiences of individual when change has occurred. Ferlie and Pettigrew (1996) believe that organisations are often seen as driven by the search for legitimacy rather than for efficiency.

\subsection{Poor Performance and Reorganisation}

In old organisations, several factors may combine to produce poor performance, one factor is the average length of service of employees, making it difficult for them to react to change and resistant to attempts change them. Ayub and Hegstard (1986) suggested that poor performance of public industrial enterprises can be explained by some inherent differences relating to ownership. These include lack of significant financial stake on the part of the State Government officials representing the State. Limited threat of bankrupt resource to government funds and political inertial in terms of lay off of large number of employees (Mohyeldin and Suleiman, 2004).

Further studies of Ayub and Hegstard reveal that factors not strictly related to ownership are equally important. These include business and managerial environment that distinguished successful public enterprises from the poorly performing ones. If all these are managed well the performance gap between private and public enterprises can be reduced significantly (Puah and Anantharam, 2008).

\subsection{Employee Termination/Retrenchment}

There are various reasons and causes of employee termination. In general termination fall into three (3() major groups, first resignation, second dismissal and last group which cover such as special nature as mandatory retirement, death, lay-off and physical incapability to perform job (Nadia and Appelbaum, 2000).

Physical incapability to perform job is another type of termination which is initiated by the company. According to Paris this should be restricted to only those cases where an employee is incapable of fulfilling his responsibilities because of illness or injury.

\subsection{Criteria for Dismissal, Retirement and Lay-off}

Nadia also suggested various conditions for dismissals which should be clearly defined so as to assure that each manager is applying the same criteria to all employees. Lay-off could be properly classified if the following conditions exist.

- There is no enough work for the employee (redundancy).

- It is anticipated that this will be short term temporary situation.

- The supervisor intends to recall the employee as soon as the workload permits.

\subsection{Linkages between Productivity and Motivation}

Shah and Pathan (2009) in their research explores the changes in productivity with major supposition of quantifying the relationship in terms of changes in the production caused by motivation among workers in maintaining secrecy and security of confidential data Matiari Sugar Mills was used as a case study. The study concludes that changes in productivity as gains in profitability are significantly related to motivation levels at all tiers of organisation structure.

\subsection{Motivation Enhances Efficiency and Effectiveness}

Anka L. M. (2006) in his paper he reviewed essential skills needed for managers to work efficiently and effectively in an organisation. At lower level, the major need is for technical and human skill, at higher levels 
manager's effectiveness depends largely on human and conceptual skills and at top level conceptual skills becomes the most important for successful administration. The three skills above play an important role in enhancing efficiency and effectiveness in an organisation.

\section{Methodology}

Methodology is defined as a philosophy of research process which includes the assumptions and values that serve as rationale for researching conclusions.

The methods of research adopted for this study are the use of available data and survey method.

1) Instrument - Relevant data for the study was collected through the use of face to face structured interview. The questions for the interview were written before hand and asked for this same order. Another instrument used for this study is available data. Records concerning quality of service test were examined, other documents like office diary and letters were also examined.

2) Population - The total population of NIPOST Sokoto Territory as of the time of research was 200. This includes both senior and junior staff.

3) Sample - A connivance sample of 50 out of total 200 were interviewed.

4) Method of Data Analysis - Cross tabulation and simple percentage method of data analysis was used. However, descriptive method was used to analyse some of the data.

\section{Theoretical Frame Work}

Theories guiding this research work are woven around the question why rationalisation? Rationalisation is inevitable in Nigerian public service because there is low productivity in almost all sectors of public service.

The main reason of the failure of the civil service is because integration between organisational goal and individual goal is not balanced. The goal and individual such as pleasure, search for security to overwhelm the entire system thereby resulting into inefficiency. Mc Gregory (1960) proposed a set of assumptions on human motivation he calls theory $Y$ that is the integration of individual goals with that of the organisation.

This theory asserts that workers are self directing responsible and capable of self control. The theory of Argyris (1971) points to a basic dichotomy between the needs of the individual and those of the formal organisation. Agyris believes that people are inclined by nature to expand psychological energy towards some purpose and that their personal needs tend to have a priority over the needs of organisation. People use their energy to subvert the ends sought by organisation if management fails to recognise their needs.

Majority of workers in NIPOST can not meet the basic needs of life which Mashlow classified as elemental need that needed to be met before one can think of anything else. Satisfying those needs can energise and direct the behaviours of workers but since this is not done, the integration of individual goal and organisational goal have become imbalanced, resulting to inefficiency and ineffectiveness.

\subsection{Organisation Structure of NIPOST}

The hierarchal arrangement of the organisation is headed by management board. The executive board of NIPOST is made up of the Postmaster General as the Chief Executive Officer (CEO) and five Deputy Postmaster General heading the five divisions in the organisation, these are corporate services, engineering and technical services, finance, investment, operations planning and territorial administration.

The organisation maintains thirty one (31) Territorial Headquarters throughout the Federation including the Federal Capital Territory, Abuja. Sokoto Territory is one of the 31 Territorial offices under the Area Postal manager are head of Units, these are Principal Personal Officer, Principal Investigation Officer, Principal Finance Officer, Public Relations Officer and Superintendent in charge of works and maintenance, see diagram, Figure 1. 


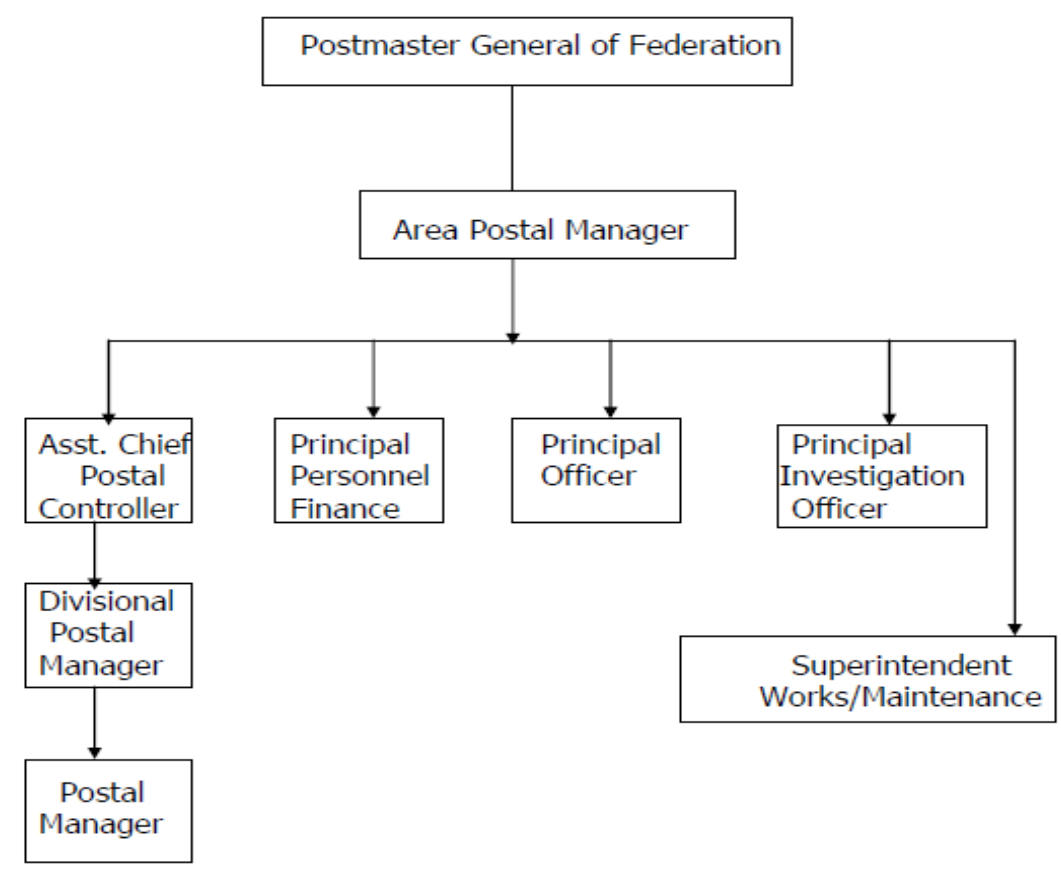

Figure 1. Organisational structure of NIPOST

\section{Results and Discussion}

Information concerning how to answer the questions associated with staff rationalisation in NIPOST Sokoto Territory was derived from structured interview conducted with management and senior staff of the Territory. Also available records on quality of service test for years 2008. 2009 and 2010 January to March were examined. The Area Postal manager and all heads of Unit who form the management team were interviewed. Most of the respondents were willing to give answers to the questions asked because they saw the interview as a means of expressing their grievances and feelings about staff rationalisation in NIPOST. The data collected was grouped into three groups based on the objectives of the study.

\subsection{Rationalisation, Efficiency and Effectiveness in NIPOST Sokoto Territory}

Some of the $t$ and senior staff of the Territory believe that staff rationalisation in NIPOST was mainly to cut down expenses, to reduce redundancy of staff to source for money and seek for efficiency and effectiveness so as to be ready for commercialisation.

Table 1. Rationalisation and improvement of postal service

\begin{tabular}{lccc}
\hline & Response & Number & Percentage \\
\hline Yes & 35 & $70 \%$ \\
No & 15 & $30 \%$ \\
Total & 50 & $100 \%$ \\
\hline
\end{tabular}

Source: Survey results, 2010

Seventy percent of respondents are of the opinion that there is improvement of postal services in NIPOST. Thirty percent are of the view that there is no improvement in the services of NIPOST. According to $70 \%$ of the respondents, the major area of improvement is the delivery of mails by postmen.

Table 2. Quality of service test Sokoto territory 2008, 2009 and 2010

\begin{tabular}{lcc}
\hline Year & Mean (Transit Time) & Remark \\
\hline 2008 & 4.28 & \\
2009 & 4.45 & \\
2010 & 2.75 & \\
\hline
\end{tabular}

Source: Survey results, 2010

The table above shows the average of transit time for postal items posted in other Territories to Sokoto the 
headquarters of Sokoto Territory. In the year 2008 from January to October before the rationalisation exercise, postal items received in Sokoto Territory from other Territories of the Federation took an average of 4.28days to arrive Sokoto. In 2009 such items spent an average of 4.45days before reaching Sokoto. In 2010 from January to March, postal items especially letters spent an average of 2.75 transit time.

Based on the above data, one could say that there is an improvement in the services of NIPOST because the average transit time in 2008 before the rationalisation and 2009 change from 4days to an average of 2 daysin 2010. Although there is an improvement in the services of NIPOST, the researcher believes this has brought efficiency and effectiveness because the target of transit time in NIPOST is 2days for conventional mail while 1 day for speed post.

Table 3. Workers ability to cope with their job

\begin{tabular}{|c|c|c|}
\hline Response & Number & Percentage \\
\hline Yes & 7 & 77.17 \\
\hline No & 2 & 22.22 \\
\hline Total & 9 & $100 \%$ \\
\hline
\end{tabular}

Source: Survey results, 2010

In Table 3, respondents were asked now that the number of staff in your Unit has reduced, are the remaining workers able to cope with their jobs. Seven heads of unit answered yes while one manager said workers in his unit no longer shift responsibility to one another. Most of the junior staff in NIPOST Sokoto Territory is of the view that they cope with their normal duties. However, they said to be more efficient and effective, they should be motivated by both their supervisors and their directors.

\subsection{Rationalisation and Discipline in NIPOST Sokoto Territory}

Based on records from Personnel and Investigation Units, the major acts of indiscipline in the Territory pilfering of items, truancy and embezzlement see Table 4.

Table 4. Rationalisation as a means of instilling discipline in NIPOST Sokoto territory

\begin{tabular}{lccc}
\hline & Response & Number & Percentage \\
\hline Yes & 42 & $84 \%$ \\
No & 8 & $16 \%$ \\
Total & 50 & $100 \%$ \\
\hline
\end{tabular}

Source: Survey results, 2010

When asked if staff rationalisation has instilled discipline in NIPOST Sokoto Territory, $84 \%$ of the people interviewed said yes. However $16 \%$ of the workers said No because there are people who still engage in pilfering embezzlement and truancy. Taskforce is one of the instruments used to bring about improvement in NIPOST with the creation of Taskforce on Post and Telecommunications, a lot of people who had postal offences have been dismissed, it is now more difficult for people who commit a crime to go unpunished and so people are committed to do their jobs. Eighty four percent of the people believe that workers now play less truancy compared to the period of rationalisation.

Table 5. Change of workers attitude towards their jobs

\begin{tabular}{lccc}
\hline & Response & Number & Percentage \\
\hline Yes & 36 & $72 \%$ \\
No & 14 & $28 \%$ \\
Total & 50 & $100 \%$ \\
\hline
\end{tabular}

Source: Survey results, 2010

Seventy two percent of the staff interviewed are of the opinion that there is a great change of workers attitudes towards their job because of the fear to loose their jobs. Twenty eight percent of the respondents said workers do not seem to show any change in attitude because they believe they will not loose much if they are retrenched since the salaries are small and are not paid as at when due. Some of the junior staff are of the view that workers are not motivated in NIPOST and so cannot put in their best. 


\subsection{Criteria for Rationalisation}

According to available records and interview conducted the criteria for retrenchment in NIPOST which applies to Sokoto Territory range from old age, length of service, redundancy of staff, negligence to duty and record of any act of indiscipline either in terms of postal crime or fighting on duty.

Table 6. All people retrenched in NIPOST Sokoto territory were rightfully retrenched

\begin{tabular}{|c|c|c|}
\hline Response & Number & Percentage \\
\hline Yes & Nil & Nil \\
\hline No & 50 & $100 \%$ \\
\hline Total & 50 & $100 \%$ \\
\hline
\end{tabular}

Source: Survey results, 2010

All people interviewed agreed that not all staff affected by rationalisation were justified for retrenchment. The answer to the question - do you think all people retrenched in Sokoto Territory were justified for retrenchment shows that $100 \%$ of the respondents believed that not all retrenchment were rightly done because there are cases in some units of the Territory where investigation teams did not handle cases very well. Some of the junior and senior staff believed that workers were victimised by their enemies as peoples names were replaced by others not really due to be retrenched. The interview also reveals that some hard working staffs that were not justified by the criteria suggested were affected while those found wanting still remain in the department.

According to responses, majority of the respondents said those retired based on length of service reached neither thirty five years nor retirement age. Most of them fall between $15-30$ years of age. Based on my observation and other NIPOST staff retrenchment has not affected NIPOSDT officers from Management Cadre Level 13 and above. Most of the respondents believe there was politics in the whole exercise.

Available records shows that 75 junior staff from Sokoto Territory lost their jobs either through retirement or dismissals, 10 senior staff have lost their jobs through the same forms of termination. According to information gathered, 10 retrenched staff from Sokoto Territory were recalled and have since resumed duty. Also $100 \%$ of the staff interviewed agreed that 10 people were recalled after rationalisation exercise.

\subsection{Problems and Observation Noted during this Research}

- This research reveals that there exist different postal crimes in NIPOST; one of the crimes that exist in Sokoto Territory is postal order or money order pilfering.

- It was discovered, during this research in Sokoto Territory that $90 \%$ of the retrenched staffs are yet to receive their termination benefits.

- Interview conducted during this research reveals that the major problem that exists is mistrust amongst workers.

- Another problem discovered is there is no autonomy in operation especially in commercial oriented units like expedited mail service where there is high competition with private counter companies. According to the manager in charge there is no chance given to study market forces which determine the business.

- It was discovered that there is resistance to change especially introduction of new ideas, the department seems to stick to its old ways of doing things. There seems to be no flexibility in mode of the $21^{\text {st }}$ century.

\section{Summary, Conclusions and Recommendations}

\subsection{Summary}

The study examined the views of junior and senior staff of NIPOST Sokoto Territory concerning staff rationalisation in public service with reference to NIPOST Sokoto Territory. To achieve this, the study examined the criteria and reason for staff rationalisation, the effects of rationalisation and the category of staff affected in NIPOST Sokoto Territory.

The research is based on information obtained from available records, personal observation and interview conducted. In the course of the interview it was discovered that the main reason for staff rationalisation is to cut down expenses. Other reasons are to reduce redundancy of staff to source for money and to prepare the department towards commercialisation. 


\subsection{Conclusion}

The major conclusions drawn from this research were:

- Seventy percent of respondents are of the view that there is improvement in postal services of NIPOST. Thirty percent agreed that there was no improvement. According to seventy percent of the respondents, the major area of improvement was in the delivery of mails by postmen.

- The average transit time in 2008 before rationalisation changed from 4days to 2days in 2010. Although there is an improvement in the services of NIPOST, but the researcher believe that has not brought about efficiency and effectiveness because the target time for delivery of mails is 24hours.

- About $84 \%$ of the respondents agreed that staff rationalisation has instil discipline in NIPOST Sokoto Territory, while $16 \%$ of the respondents said No because some people still engage in pilfering, embezzlement and truancy.

- Seventy two percent of sampled respondents agreed that there is a great change in workers attitude towards their jobs because of fear of being retrenched. $28 \%$ believed that workers do not seem to show any change in attitude because they believe it makes no difference if they are not retrenched because the salaries are very low.

- One hundred percent of the respondents are of the opinion that not all retrenchments were rightly done because some junior staff were victimised by their enemies as people names were replaced by others not really due to be retrenched.

- According to my observation and other NIPOST staff retrenched has not affected NIPOST Officers in Managerial Cadre Grade Level 13 and above. Most of the respondents believe there was politics in the whole exercise.

- Available records shows that 75 junior staff from Sokoto Territory lost their jobs either through retirement or dismissal, about 10 senior staff lost their jobs in the same form of termination. About 10 staff was recalled after the rationalisation exercise.

Finally, efficiency and effectiveness have not been achieved in NIPOST Sokoto Territory because rationalisation was not properly carried out. Therefore null hypothesis $\mathrm{H}_{\mathrm{o}}$ is accepted and Alternate Hypothesis $\mathrm{H}_{\mathrm{A}}$ is rejected.

\subsection{Recommendations}

On the basis of the above conclusions the following recommendations are made:

- NIPOST seems to be neglected by the government to prepare the depart6ment towards commercialisation; government should release funds for purchase of new vehicles and postal equipment to replace the obsolete ones.

- There should be autonomy in operation especially in expedited mail service. Managers in this section should be given the opportunity to study market forces which determine the business.

- Government should give NIPOST free hand to fix tariff.

- NIPOST should try as much as possible to be flexible with their policies where necessary so as to motivate efficiency and effectiveness.

- It is recommended that hardworking staff should be rewarded, salaries should be paid as at when due and condition of service should be improved

- NIPOST activities should be computerised, manual date stamping should be replaced by cancelling machines, manual sorting of mails should be replaced by machines. This will minimise cost and maximise profit. In this regard efficiency and effectiveness will be achieved in the long run.

- It is important to encourage training and retraining of staff to prepare them for commercialisation.

\section{References}

Anka L. M. Anka. (1988, March-April). Corporate Objectives and Self Development. The Specialist International, Journal of Institute of Management Specialist Warwickshire, England, 3(5).

Anka L. M. Anka. (1992). Management by Objectives as an Effective Management Tool. Pakistan Management Review Journal of Pakistan Institute of Management, XXVII(IX), 1992.

Anka L. M. Anka. (2006, Fourth Quarter). Motivational Skill Acquisition for Managers. Pakistan Management Review, XLIII(4).

Ayub, \& Hegstard, (1986). Public Industrial Enterprises, Determinants of Performance, Industrial and Financial 
Series, Vol. 17 WDC.

Dia, A. (1977). African Management in the 1990s and Beyond. TROKO, 2(3).

Ferlie, E., \& Petigraw, A. (1996). The Nature and Transformation of Corporate Headquarters: A Review of Recent Literature and Research Agenda. Journal of Management, 33(4).

Fundi, N., \& Otter. (1996). Public Sector Transformation Rethinking Markets and Hierarchies in Government. Amsterdam John Benjamin's publishing Company.

Mc Graw Hill. (1965). Dictionary of Modern Economics: A Handbook of Terms and Organisation, USA.

Mohyeldin, A., \& Suleiman, T. (2004, Fourth Quarter). Self and Supervisors Rating of Performance. Pakistan Management Review, XLI(4), 70-85.

Nadia, L., \& Appelbaum, S. H. (2006, Second Quarter). The Impact of Downsizing Practices on Corporate Success. Pakistan Management Review, XLIII(2).

NIPOST. (2005). Annual Report of the Nigerian Postal Service: Federal Republic of Nigeria.

NIPOST. (2010). Annual Report of the Nigerian Postal Service: Federal Republic of Nigeria.

Puah, P., \& Ananthram. (2008, Second quarter). Exploring the Antecedents and Outcomes of Career Development Initiatives: Empirical Evidence from Singapore an Employees. Pakistan Management Review, $X L V(2)$. 